\title{
KADAR REALISME MAGIS DALAM CERPEN DI TUBUH TARRA DALAM RAHIM POHON KARYA FAISAL ODDANG
}

\author{
Hasina Fajrin R, Sarwo Ferdi Wibowo \\ Balai Bahasa Sulawesi Selatan \\ Balai Bahasa Bengkulu \\ hasinafajrinr@gmail.com \\ sarwoferdiwibowo.sfw@gmail.com
}

\begin{abstract}
Abstrak
Secara sosial-kebudayaan, masyarakat Indonesia hingga hari ini masih sangat dekat dengan mitos dalam kesehariannya. Mitos-mitos tersebut dapat menjadi sumber inspirasi bagi sastra Indonesia dalam memberikan kekhasan khususnya pada gaya narasi sastra Indonesia seperti dalam cerpen $D i$ Tubuh Tarra dalam Rahim Pohon karya Faisal Oddang. Dalam tulisan ini, kualitas realisme magis yang memungkinkan bersatunya elemen riil dan magis dalam gaya narasi yang merupakan sebuah genre baru dalam sastra Indonesia diungkap. Penelitian ini menggunakan teori realisme magis Wendy B. Faris sebagai pisau analisis untuk menentukan kadar realisme magis dalam cerpen. Penentuan kadar realisme magis ini dilakukan dengan menentukan unsur magis, riil, dan penggabungan kedua unsur tersebut. Hasil penelitian menunjukkan 1) adanya elemen-elemen tak tereduksi, dunia yang fenomenal, keragu-raguan antara magis dan riil, penggabungan dunia-dunia, dan kekacauan waktu, ruang dan identitas berupa objek, karakter, dan peristiwa serta 2) relasi antarelemen menunjukkan bahwa objek, karakter, dan peristiwa antara yang banyak mendominasi karya ini sehingga dapat disimpulkan bahwa kadar realisme magis cerpen ini cukup kuat untuk dikategorikan sebagai karya realisme magis.
\end{abstract}

Kata kunci: realisme magis, Toraja, Faisal Oddang

\section{Magical Realism in Di Tubuh Tarra dalam Rahim Pohon Short Story by Faisal Oddang} Abstract

Indonesian society, socially and culturally, is still pretty closed with myth in their life today. The myths could become an inspiration for Indonesian literature in influencing the characteristic of Indonesian narrative like Di Tubuh Tarra dalam Rahim Pohon's short story by Faisal Oddang. In this writing, the quality of magic realism that enables the real and magic element merging in the narrative which is a new genre in Indonesian literary is uncovered. The quality of magic realism is done by determining the magic, real, and the emerging of both elements. It applies magical realism Wendy $B$. Faris to analyze the magic realism quality of the short story. Having been analyzed, the result found that 1) there are irreducible elements, phenomenal world, the unsettling doubts, merging realms, and the disruption of time, place and identity through object, character, and events and 2) the interrelation of elements uncover that in-between object, character, and events dominate much the short story so it could be concluded that magic realism quality of the short story is strong enough to categorize it as magic realism literary.

Keywords: magical realism, Toraja, Faisal Oddang

\section{PENDAHULUAN}

Cerpen Di Tubuh Tarra dalam Rahim Pohon merupakan cerpen pertama yang ditulis Faisal Oddang dan berhasil memenangkan Cerpen Terbaik Kompas tahun 2014. Kelebihan cerpen ini adalah tema lokalitas yang mencerminkan keragaman Indonesia. Selain itu, cerpen ini juga menjadi kontribusi para juri yang terdiri atas Frans Sartono, Hariadi Saptono, Myrna Ratna, Putu Fajar Arcana, dan Efix Mulyadi dalam mendorong tumbuhnya karya seni yang kuat dan merayakan keunikan Indonesia.
Diterbitkan dalam buku Cerpen Pilihan Kompas 2014: Di Tubuh Tarra dalam Rahim Pohon pada tahun 2016, cerpen ini menceritakan tentang bayi yang dikubur di dalam batang pohon dan menggambarkan interaksi bayi-bayi sesama penghuni pohon yang datang dari kelas sosial berbeda, bergantung posisinya di dalam pohon --paling atas berarti kelas sosialnya adalah tokapua, kemudian tomakaka, lalu tobuda--. Dunia roh dan dunia manusia dinarasikan sedemikian apik, sehingga pembaca fiksi empiris menganggap hal-hal magis yang terjadi 
dalam cerpen ini masih tetap dapat diterima nalar.

Karena mengangkat lokalitas Toraja yang memiliki tradisi mengubur bayi di pohon ataupun batu, dan bahkan menyimpannya di tongkonan selama mungkin sampai keluarga yang ditinggalkan dapat melakukan ritual penguburan karena membutuhkan biaya puluhan juta, bahkan miliaran, tergantung kelas sosial, cerpen ini menarik dikaji menggunakan realisme magis. Berdasarkan kata yang membangunnya, istilah realisme magis bersifat kontradiktif, realisme merujuk kepada hal yang riil, sementara magis kepada fantasi. Akan tetapi, demikian halnya dengan objek yang akan dikaji di dalam tulisan ini, ada percampuran modernitas dan tradisional, realitas dan mitos, sastra dan legenda. Hal ini merupakan upaya memberikan perhatian pada segala yang ditepikan oleh modernitas.

Masyarakat tradisional Indonesia hingga hari ini masih mempercayai banyak mitos yang berakar dari tradisi mereka. Sejak kelahirannya, sastra Indonesia yang mengaku diri sebagai sastra modern tidak memberi tempat pada narasi-narasi magis yang berakar pada tradisi Indonesia. Salah satu catatan sejarah yang membuktikan hal ini adalah Pidato Kebudayaan (Muchtar Lubis, 2017) di Taman Ismail Marzuki pada 6 April 1977 yang pada poin keempat menggambarkan sifat manusia Indonesia yang percaya tahayul. Sastra Indonesia modern kemudian dalam perkembangannya memilih aliran realis yang menjawab semangat dari modernitas, sehingga karya sastra Indonesia menjadi sesuatu yang terkesan empirik. Hal ini diterjemahkan dari maraknya penggunaan kriteria logika cerita dalam berbagai lomba menulis sastra yang mensyaratkan sebuah narasi mesti masuk akal.

Sementara itu, di belahan bumi lain di Selatan Benua Amerika, para pengarang seperti Carpentier dan Borges membuka pandangan baru bahwa realisme merupakan pengaruh dari proyek pencerahan kolonial yang mencabut masyarakat jajahan dari tradisi mereka. Karya-karya penulis Amerika latin seperti The Kingdom of this World karya Carpentier kemudian memasukkan unsur magis dalam narasinya hingga menjadi genre realisme magis hingga mencapai puncak kepopulerannya melalui karya Gabriel Garcia Marques, One Hundred Years of Solitude.

Dalam sebuah wawancara, pertanyaan mengapa Eropa tidak dapat menangkap realisme magis ini pernah ditanyakan. Gabriel Márquez langsung menjawab, "Ini pasti karena rasionalisme mereka mencegah mereka melihat realitas yang tidak sebatas pada harga tomat dan telur" (Gabriel Garcia Marquez, 2014). Pernyataannya ini mengandung perlawanan sekaligus menegaskan kelebihan dari realisme magis yaitu memberikan pandangan yang mendalam terhadap hal yang dimaknai sebagai kenyataan dan membuka selubung logika yang menjadi arus utama dalam memaknai kenyataan tersebut. Dalam hal inilah realisme magis mampu memfasilitasi karya-karya seperti cerpen Di Tubuh Tarra dalam Rahim Pohon karya Faisal Oddang sebagai sebuah karya seni yang berkualitas karena sejalan dengan apa yang disampaikan oleh Camayd-Freixas yang memahami realisme magis pada penulis Amerika Latin sebagai ekspresi estetik dari paham primitif yang melayani kerinduan penulis Amerika Latin akan identitas dan emansipasi kultural (Warnes, 2009: 5).

Berdasarkan penjabaran di atas, unsur magis dalam realitas tradisional Toraja dalam cerpen Di Tubuh Tarra dalam Rahim Pohon menarik untuk dikaji dari sudut 1) bagaimana magis dan riil dinarasikan dalam cerpen Di Tubuh Tarra dalam Rahim Pohon menggunakan elemen-elemen karakteristik realisme magis, dan 2) bagaimana hubungan antarelemen dan kadar realisme magis cerpen Di Tubuh Tarra dalam Rahim Pohon? 
Setelah mengetahui elemen-elemen realisme magis yang dinarasikan dalam cerpen dan hubungan antarelemen-elemen tersebut, kadar realisme magis dapat ditentukan. Selain itu, tulisan ini juga diharapkan dapat memberikan gambaran bahwa realisme magis memang ada di masyarakat dan telah lama berkembang dalam tradisi Indonesia, tetapi masih sedikit penulis yang tertarik untuk menghadirkannya dalam karya sastra.

\section{KERANGKA TEORI}

Realisme magis sering diasosiasikan dengan penulis-penulis Amerika Latin karena mereka yang membuat istilah tersebut populer. Padahal, istilah tersebut diciptakan oleh kritikus seniman Jerman Franz Roh pada tahun 1925. Akan tetapi, istilah tersebut digunakan untuk merujuk gaya lukisan yang dianggap memiliki bentuk yang berbeda dari surealisme. Istilah tersebut kemudian memengaruhi sastra Eropa dan Amerika, dan akhirnya dimasukkan sebagai bagian dari sastra pada tahun 1950.

Dalam perkembangannya, ada dua tren realisme magis. Tren pertama realisme magis berfokus pada teks dan analisis unsur-unsur yang membangun teks, dan tidak menghubungkannya dengan unsurunsur di luar teks. Tren kedua berfokus pada teks dan menghubungkannya dengan unsur-unsur di luar teks, misalnya politik, sosial, budaya, pengarang, dan pembaca (Marisa Bortolussi, 2011: 282).

Beberapa pakar mendefinisikan realisme magis, salah satunya Maggie Ann Browers. Dia menyatakan bahwa kunci untuk memahami realisme magis bekerja adalah dengan memahami cara naratif dikonstruksi agar tersedia konteks yang realistis bagi peristiwa-peristiwa magis dalam fiksi (Maggie Ann Browers, 2005). Selain Ann, definisi realisme magis juga dinyatakan sebagai "magical realism combines realism and the fantastic so that the marvelous seems to grow organically within the ordinary, blurring the distinction between them" (Wendy B. Faris, 2004).

Pernyataan tersebut menegaskan bahwa realisme magis menggabungkan realitas dan fantastis sehingga hal-hal luar biasa tampaknya tumbuh secara organik, dan mengaburkan perbedaan realitas dan fantastis. Secara fundamental, ada dua tipe realisme magis, yakni: 1) tipe surealistik ilmiah yang utamanya ditemukan dalam tulisan dan mitos Eropa, dan 2) tipe folklor yang diperkuat oleh orang Amerika Latin (Albert Sheqi, 2013: 8).

Meskipun banyak definisi mengenai aliran atau genre ini, bahkan tidak jarang dikaitkan dan ditumpangtindihkan antara realisme dan magis, tulisan ini akan menerapkan realisme magis seperti yang diajukan Wendy B. Faris. Hal ini berdasarkan pertimbangan bahwa ide realisme magis ini dikembangkankan dengan berfokus pada banyak novel, di antaranya: Juan Rulfo, Pedro Paramo (1955), Gunter Grass, The Tin Drum (1959), Wilson Harris, Palace of the Peacock (1960), Gabriel Garcia Marquez, One Hundred Years of Solitude (1967), Milan Kundera, The Book of Laughter and Forgetting (1979), Salman Rushdie, Midnight's Children (1980), Patrick Suskind, Perfume (1985), dan Toni Morrison, Beloved (1987) (Wendy B. Faris, 2004). Selain itu, tulisan ini hanya berfokus pada kadar realisme, dan karakteristik realisme magis atau bukan juga telah dikemukakan Faris.

Sekaitan dengan kadar realisme magis, Wendy B. Faris mengajukan beberapa karakteristik yang dapat digunakan untuk memisahkan riil, magis, dan gabungan riil magis dalam karya sastra untuk menentukan kadar realisme magis sebuah karya. Berikut pemaparannya.

\section{Elemen-elemen yang Tidak Tereduksi (Irreducible Elements)}

Elemen-elemen yang tidak tereduksi merupakan sesuatu yang tidak dapat dijelaskan menurut paham empirisme barat bahwa diperlukan penjelasan berdasarkan 
pada logika, pengetahuan yang dikenal, atau kepercayaan yang diwarisi. Sebagai akibatnya, pembaca sulit menyimpulkan pertanyaan tentang status dari peristiwa dan karakter dalam karya fiksi tersebut (Wendy B. Faris, 2004: 7). Karakteristik ini menitikberatkan terhadap suatu kejadian nyata yang terjadi dalam kehidupan namun tidak dapat dipercaya oleh akal manusia sebagai mahluk yang berlogika. Dalam karya sastra ciri ini, dapat dilihat pada diterimanya zombie untuk hidup berdampingan dengan manusia dalam One Hundred Years of Solitude.

\section{Dunia yang Fenomenal (The Phenomenal World)}

Dunia yang fenomenal adalah deskripsi dunia secara panjang lebar dan terinci yang mengandung unsur keluarbiasaaan. Dunia ini menyajikan kesan nyata dalam realisme magis dan menggambarkan keberadaan unsur fenomenal melalui dunia, tokoh, tempat, dan peristiwa yang diceritakan secara rinci dan realistis. Perubahan tokoh budak menjadi kupu-kupu dalam karya Carpentier dapat dikemukakan sebagai contoh ciri ini.

\section{Keraguan yang Tak Tuntas (The Unsettling Doubts)}

Keraguan yang tak tuntas tersirat dari pernyataan "magical realists scenes may seem dreamlike, but they are not dreams, and the text may both tempt us to co-opt them by characterizing them as dreams and forbids that co-option" (Wendy B. Faris, 2004). Ini mengimplikasikan bahwa adegan yang ditemukan dalam realisme magis dampak terlihat seperti mimpi padahal sebenarnya bukan mimpi. Teksnya juga sekaligus mengooptasi dan melarang kooptasi dengan mengategorikan adeganadegan tersebut seolah-olah mimpi.

Pada karakteristik ini seakan kejadian magis yang terjadi diragukan sekaligus dibenarkan. Ini diperkuat dengan pernyataan Faris yang mengatakan bahwa realisme magis itu seperti mimpi, namun di sisi lain ada pendapat yang membenarkan kejadian tersebut.

\section{Penyatuan Dunia-Dunia (Merging Realms)}

Merging realms adalah penggabungan dua alam. Penggabungan dua dunia ini dapat berupa pertemuan antara dunia tradisional dengan yang modern atau yang magis dengan material atau secara umum, realisme magis menggabungkan realisme dengan fantastik (Wendy B. Faris, 2004: 21). Merging realms juga menjelaskan kejadian yang dapat diterima akal bahwa magis itu ada. Ciri utama dalam realisme magis adalah penggabungan dua dunia ini dilakukan tanpa mengistimewakan salah satunya.

\section{Kekacauan Waktu, Ruang, dan Identitas (Disruption of Time, Space, and Identity)}

Konsep waktu, ruang, dan identitas yang berlaku di masyarakat dilanggar dalam narasi realisme magis (Wendy $\mathrm{B}$. Faris, 2004: 23). Hal ini terjadi karena adanya hal-hal magis yang hadir dalam dunia nyata. Hadirnya hal-hal magis dalam dunia nyata menandakan bahwa konsep ruang dan waktu magis menembus ke dalam dan dirembesi oleh ruang dan waktu riil.

\section{METODE PENELITIAN}

Metode merupakan langkah yang akan digunakan dalam mengumpulkan dan menghubungkan relasi antardata. Data dapat berupa kata, teks, frasa, paragraf, dan wacana yang kemudian dianalisis relasi antarsatuan-satuannya (Faruk, 2012). Oleh karena objek formal tulisan ini adalah realisme magis, datanya berupa benda, objek, peristiwa riil dan magis dalam cerpen Di Tubuh Tarra dalam Rahim Pohon karya Faisal Oddang yang kemudian dipilah antara yang riil, magis, dan yang riil dan magisnya menyatu sehingga sulit dibedakan. 
Hasina Fajrin R. ${ }^{1}$ dan Sarwo Ferdi Wibowo ${ }^{2}$ : Kadar Realisme Magis dalam Cerpen di Tubuh Tarra dalam Rahim Pohon Karya Faisal Oddang

\section{PEMBAHASAN}

\section{Ciri Realisme Magis dalam Di Tubuh Tarra dalam Rahim Pohon}

Dalam menganalisis kadar realisme magis cerpen Di Tubuh Tarra dalam Rahim Pohon, digunakan lima karakteristik realisme magis yang dikemukakan Wendy B. Faris yang telah dijelaskan dalam kerangka teori. Karakteristik tersebut digunakan untuk mengungkap bagaimana Faisal Oddang memadukan unsur realis dan unsur magis dalam karyanya. Suatu karya realisme magis dapat dikatakan berhasil jika menempatkan unsur-unsur magis sebagai sesuatu yang setara dengan unsur realis dalam narasinya. Kriteria tersebut yang akan menjadi penentu kadar realisme magis cerpen karya Faisal Oddang tersebut.

Cerpen ini dibuka dengan deskripsi suatu lokasi yaitu Passiliran, secara kontradiktif tempat ini digambarkan memiliki sifat yang menyerupai ibu, karena memiliki kemampuan memeluk anak-anaknya. Tempat ini juga, serupa ibu, menjadi tempat menyusu anak-anaknya, tetapi apa yang mereka susui merupakan getah. Deskripsi selanjutnya menjelaskan mengenai daur hidup anak-anak di Passiliran itu yang akan berubah menjadi seperti ibu mereka, makam bagi bayi-bayi yang belum tumbuh giginya di Toraja.

Pada catatan kaki ditemukan bahwa Passiliran merupakan makam bagi bayi yang dibuat di pohon tarra yang memiliki diameter besar. Fakta ini menjelaskan posisi sifat keibuan pohon tarra bukan bentuk personifikasi dalam narasi, melainkan sebuah fakta yang berakar dari suatu kebudayaan yaitu kebudayaan Toraja. Konteks inilah yang menempatkan pemahaman tentang pohon tarra sebagai ibu bagi bayi-bayi belum bergigi yang telah meninggal, merupakan suatu yang dipercaya sebagai hal yang nyata dalam masyarakat Toraja, meskipun hal ini tidak dapat diterima dalam paradigma berpikir logis. Dalam perspektif realisme magis, pohon tarra ini tergolong sebagai elemen yang tidak tereduksi. Hal yang menarik untuk dicermati adalah bagaimana strategi narasi yang digunakan dalam memperkenalkan Tarra dalam cerita.

Di Passiliran ini, kendati begitu ringkih, tubuh Indo tidak pernah menolak memeluk anak-anaknya. Di sini, di dalam tubuhnya_ bertahun-tahun kami menyusu getah. Menghela usia yang tak lama. Perlahan membiarkan tubuh kami lumat oleh waktu_ menyatu dengan tubuh Indo. Lalu kami akan berganti menjadi ibu_makam bagi bayi-bayi yang meninggal di Toraja. Bayi yang belum tumbuh giginya. Sebelum akhirnya kami ke surga (Faisal Oddang, 2016).

Selain dari penjelasan pada catatan kaki, wujud nyata tarra berupa pohon sebagai unsur riil terindikasi dari kata 'getah' dalam teks. Pohon yang dipahami sebagai ibu, memberikan susu berupa getah pada anak-anaknya. Paradigma magis yang memahami benda memiliki sifat keibuan dipadukan dengan paradigma logis yang percaya bahwa pohon hanya menghasilkan getah bukan susu. Anakanak yang menyusu getah menjadi satu penanda bahwa narasi cukup berhasil menampilkan unsur realis dan unsur magis sebagai satuan yang saling berkelindan dalam struktur narasinya.

Hal ini secara konsisten ditemukan dalam lanjutan cerita ketika ada mayat bayi baru yang dimasukkan ke dalam Passiliran. Lanjutan cerita ini memberi penegasan bahwa Passiliran merupakan bagian dari dunia nyata, karena dipadankan dengan surga yang kemudian. Tarra merupakan tempat persinggahan arwah bayi-bayi itu sebelum menjadi surga. Karena keberadaannya di dunia nyata, kondisi dunia nyata mempengaruhi kehidupan bayi-bayi di dalam tarra, seperti perkembangan struktur sosial.

Sudah kuduga, kau keturunan tokapua, makammu harus diletakkan di tempat yang tinggi. Padahal kau, aku, dan anak-anak 
Indo yang lain, kelak di surga yang sama.

Pagi-pagi sekali kau berdiri di ambang bilik-mengetuk pintu ijukku yang rontok sebab bertahuntahun tak diganti.

"Boleh masuk?"

Aku mengangguk, takut salah bicara dan kau akan murka. Bagi tomakaka sepertiku, tak ada yang lebih hina dari salah bertutur kepadamu (Faisal Oddang, 2016).

Status sosial masih berlaku di dalam Palissiran yang pada teks ditemukan dalam istilah lokal Toraja yaitu tokapua dan tomakaka, selain itu ada tobuda. Relasi tokapua-tomakaka tidak simetris karena tomakaka lebih rendah dari tokapua sehingga dia dapat terhina hanya karena perkara salah bertutur. Namun secara kontradiktif, keadaan di dalam tarra tidak mengindahkan aturan-aturan dunia nyata seperti perkembangan psikologis seiring waktu. Bayi-bayi yang bisa berbicara dalam cerita tersebut, memahami struktur dan peran sosial, bahkan bisa merasakan cinta menyalahi aturan umum yang dipahami dalam paradigma berpikir logis, seperti yang dapat disimak dalam kutipan berikut.

"Maaf," bukamu, "sudah seminggu saya di sini, tapi saya sepertinya masih sangat asing."

"Saya dan anak-anak Indo yang lain juga minta maaf, kau tahulah kami ini hanya tomakaka, bahkan ada tobuda, tak seberapa nyali kami untuk melancangi kaum junjungan sepertimu” (Faisal Oddang, 2016).

Usaha untuk mengooptasi kemampuan berbicara bayi mengalami kebuntuan karena tidak dapat dijelaskan oleh logika modern. Bayi pada usia tersebut hanya dapat mengoceh dalam bahasa yang hanya dimengerti bayi, bukan bahasa yang didengar sehari-hari. Namun, narrator voice menceritakannya seperti perbincangan bayi tersebut adalah peristiwa yang biasa saja. Bayi seperti digambarkan memiliki dunianya sendiri, sehingga peristiwa perbincangan kedua mayat bayi tersebut meski tampak luar biasa, tetapi dapat diterima oleh logika empiris Barat karena ada kemungkinan perbincangan tersebut dapat terjadi, hanya saja kecanggihan pengetahuan belum mampu menjangkaunya, tetapi peluang itu terjadi masih dianggap besar.

Tidak hanya berbicara, Runduma, nama mayat bayi itu, juga layaknya manusia yang masih hidup. Dia dapat menangis, jatuh cinta, dan dapat melihat dunia manusia. Dia dapat melihat ayahnya datang mengunjungi pohon Tarra, sementara tidak demikian dengan ayah Runduma yang saat itu menjadi pemandu wisata di pohon tarra tersebut.

"Yang berbaju coklat, pasti itu!

"Itu Ambe," kau lesu mengatakannya. Wajahmu tampak begitu kisruh Runduma.

Kau tampak sedih hari ini. Padahal seharusnya rindumu terobati dan kau tak boleh menampung begitu banyak muram di dadamu (Faisal Oddang, 2016).

Tokoh magis kedua adalah Lola Toding. Dia adalah mayat bayi perempuan. Seperti halnya Runduma yang dapat berbicara, dapat melihat dunia manusia, Lola Toding juga memiliki perasaan pada Runduma. Setelah jasadnya telah berpisah dengan roh, dia masih dapat merasakan hal-hal yang berkaitan dengan kehidupan dunia, seperti rindu dan bahkan jatuh cinta dalam dunia roh.

Kutepuk halus pundakmu, "Ada kami dan Indo. Jangan bilang begitu."

Perasaan aneh itu bertambah hebat dan akhirnya benar-benar merisakku. Aku mencintaimu, Runduma (Faisal Oddang, 2016).

Peristiwa magis yang terjadi dalam cerpen ini adalah saat dua mayat bayi dapat beraktivitas seperti manusia pada umumnya. Peristiwa ini dianggap peristiwa 
magis karena dalam dunia riil, hal tersebut tidak mungkin terjadi. Nalar empiris akan sulit menerima sesuatu yang tak bernyawa dapat beraktivitas seperti orang yang bernyawa. Secara keseluruhan dapat dikatakan bahwa dunia yang ditampilkan dalam cerita ini merupakan sebuah dunia yang fenomenal, tetapi dirasakan sebagai hal yang menyatu dengan keseharian dalam komunitas Toraja. Dalam cara yang demikian, pandangan dunia yang diatur oleh kriteria empirisme barat dihadapkan dengan pandangan dunia orang-orang Toraja yang menganggap hal-hal tersebut di atas sebagai sebuah realitas yang masuk akal dalam paradigma berpikir mereka.

Akan tetapi, penjelasan di atas menyisakan suatu hal yang mengganjal. Keberadaan Palissiran di dalam pohon tarra sebagai tempat singgah bayi-bayi yang belum bergigi sebelum menuju surga menjadi unsur yang tidak termaknai oleh teori realisme magis Faris berkaitan dengan penggabungan dunia-dunia (merging realms). Seperti yang ditemukan dalam karya-karya penulis Amerika Latin, penggabungan dunia ditandai dengan kehadiran unsur-unsur magis dalam dunia nyata tanpa adanya sekat sama sekali. Dengan bahasa yang lebih sederhana, kedua dunia tersebut bercampur baur, seperti munculnya malaikat dalam wujud orang tua, perubahan wujud menjadi hewan, mayat hidup yang berjalan-jalan, manusia bersayap, dan sebagainya yang hidup berdampingan dengan kenyataan dalam cerita.

Narasi dalam cerpen Di Tubuh Tarra dalam Rahim Pohon meskipun secara samar masih terdapat kesan bahwa dunia tersebut terpisah, setidaknya terindikasi dari kenyataan bahwa surga merupakan tempat yang berbeda dari dunia nyata dan tidak adanya interaksi antara mahluk kedua alam tersebut. Passiliran adalah dunia yang bukan dunia gaib maupun dunia nyata. Kekaburan itu tidak lahir dari penggabungan dunia seperti yang dilakukan oleh para penulis Amerika Latin seperti penjelasan di atas, tetapi dengan menciptakan sebuah dunia baru yang berada dalam ruang antara. Secara fisik Passiliran adalah sebuah pohon, tetapi secara magis lokasi tersebut merupakan ruang pengasuhan bagi bayi-bayi yang meninggal sebelum giginya tumbuh. Pendekatan narasi yang demikian menempatkan keberadaan tarra lebih dekat dengan dunia nyata karena ia merupakan fakta empiris sekaligus fakta sosial. Narasi dalam cerpen ini membawa pandangan dunia orang Toraja bahwa yang riil dan yang magis bukan dua unsur yang terpisah secara tegas, sehingga bersifat lebih orisinal dengan pemaduan kedua unsur secara lebih halus.

Cerpen ini seharusnya mencatat bahwa semua benda fisik yang dihadirkan memiliki dimensi lain sebagai unsur magisnya. Dengan kata lain, kenyataan yang dipahami dalam cerpen ini tidak memberikan garis pemisah yang tegas antara benda nyata (yang tertangkap indra/empirik) dengan kualitas kemagisan yang melekat padanya, sehingga kedua unsur tersebut bersebati dalam setiap objek dalam cerita. Dari sudut pandang ini, dunia fenomal dalam cerpen Di Tubuh Tarra dalam Rahim Pohon merupakan bagian riil realisme magis yang menghindarkan fiksi terlalu jauh di dunia fantasi sehingga benar-benar meninggalkan dunia riil. Kategori dunia fenomenal hadir di dalam cerpen untuk tetap mempertahankan bahwa magis dihadirkan memang karena benarbenar riil dan bukan karena fantasi.

Benda pertama yang dikategorikan sebagai benda yang riil adalah pohon tarra. Pohon ini hanya ditemukan di Desa Kambira, Toraja Utara, Sulawesi Selatan. Getahnya yang banyak disimbolisasi sebagai air susu ibu. Getah yang banyak tersebut akan mengembalikan batang pohon menjadi halus kembali setelah dua puluh tahun, sehingga dapat digunakan oleh mayat-mayat bayi yang baru. Pohon ini juga tidak mengeluarkan bau meski banyak mayat bayi dikubur pada batangnya. Pohon ini dihadirkan sebagai benda riil yang memiliki unsur magis yang 
melekat yaitu alam antara untuk menunggu mayat-mayat bayi yang dikubur di dalam batangnya.

Selanjutnya, benda riil yang lain adalah ijuk. Ijuk merupakan serabut hitam pelindung pangkal pelepah enau yang biasa digunakan sebagai tali, saringan, atau sapu. Ijuk ini digunakan untuk membungkus mayat-mayat bayi yang ditanam di dalam batang pohon tarra. Ijuk sebagai pembungkus mayat pada batang pohon tarra dihadirkan untuk memberi gambaran bahwa kuburan salah seorang bayi, yakni Lola Toding yang mulai rapuh karena telah bertahun-tahun dikubur dan ijuknya tidak diganti. Fakta tersebut memuat kesatuan antara yang riil dan yang magis ketika benda fisik berupa ijuk tersebut merupakan bagian yang memiliki relasi langsung dengan dunia magis tempat tinggal para tokoh cerita.

Benda riil yang lain adalah tongkonan. Tongkonan dalam bahasa Toraja berarti tempat duduk. Di zaman dahulu, tongkonan memiliki banyak fungsi. Akan tetapi, seiring perkembangan zaman, fungsi tongkonan saat ini selain sebagai rumah adat masyarakat Toraja, juga dijadikan tempat menyimpan mayat. Tongkonan sebagai benda riil dihadirkan untuk mengilas balik alasan pernikahan kedua orang tua Runduma yang disebabkan mereka melanggar adat. Pelanggaran hukum adat tersebut diputuskan di tongkonan tersebut.

Tongkonan tampak gegap malam itu. Suara-suara riuh. Wajah-wajah penuh peluh. Orang-orang terlibat bicara. Sesaat situasi menegang ketika seorang lelaki paruh baya memegang leher baju pemuda yang wajahnya kusut (Faisal Oddang, 2016).

Bagian pertama ini menjejakkan narasi cerpen pada dunia nyata bahwa masyarakat masih menggunakan tongkonan sebagai lokasi untuk memutuskan sesuatu. Keistimewaan tersebut karena masyarakat sekitar melekatkan kualitas kesakralan kepada tongkonan. Selain fungsi tersebut, dalam cerita tongkonan tidak dijelaskan memiliki unsur magis. Oleh karena itu, dapat dikatakan bahwa tongkonan menjadi unsur yang menambatkan narasi cerpen ini tetap dalam tataran realis. Hal yang sama ditemukan dalam keberadaan kacamata yang disebut saat Lola Toding mencari sosok ayah Runduma yang datang mengunjungi Indo bersama para turis.

Benda-benda tersebut merupakan perwakilan dari dunia riil karena dapat diklarifikasi secara logika empiris. Selain itu, penggunaannya juga sesuai dengan fungsinya dalam dunia riil. Benda-benda ini dihadirkan untuk menegaskan dunia riil. Berbeda halnya dengan tulangbelulang yang disebutkan sebagai barang yang dijual pada turis. Tulang-belulang tersebut adalah milik Lola Toding yang telah lama dikubur di situ, tetapi dia juga digambarkan sebagai makhluk magis yang beraktivitas seperti manusia. Bagi pembaca yang berasal dari sistem kepercayaan yang berbeda, keraguan ini lebih banyak dibanding yang memang menganut kepercayaan yang sama yang diceritakan dalam cerpen ini. Hal ini sangat dipengaruhi kepercayaan dan tradisi naratif setiap pembaca.

Pada akhir cerita dikisahkan bahwa Lola Toding ikut menghilang dari Passiliran saat tubuhnya dikeluarkan ambe Runduma dari pohon tarra. Hal ini menempatkannya sebagai objek yang meragukan apakah sebagai roh yang secara total merupakan mahluk dunia gaib atau mayat yang secara fisik berada di dunia riil. Pada cerita akan ditemukan pokok pemikiran orang Toraja yang menjadi dasar dari pemahaman ini.

Kudengar kabar, keluarga Allo Dopang akan mengadakan rambu solo untuk mayat tanggungannya yang masih sakit dalam tongkonan (Faisal Oddang, 2016).

Kutipan tersebut mengungkap suatu pandangan dalam kosmos orang Toraja yang menganggap mayat kerabat yang 
meninggal sebagai orang yang sedang sakit. Sebagai orang yang sakit dirinya akan tetap mengalami pertumbuhan, memiliki hasrat, dan melakukan aktivitas seperti orang biasa yang masih hidup. Lola maupun Runduma yang diletakkan di dalam pohon tarra pun demikian. Tokohtokoh yang terlibat percakapan dalam Passiliran bukanlah roh si bayi, melainkan mayat-mayat bayi itu sendiri yang dalam kosmos orang Toraja secara faktual dilihat sebagai orang yang sakit.

Pada titik ini, sebenarnya narasi dalam cerpen Di Tubuh Tarra dalam Rahim Pohon melakukan serangan pada ontologi pemahaman empirisme barat terhadap kebudayaan. Faisal Oddang dalam cerpen tersebut menempatkan koridor berpikir orang Toraja bukan sebagai pemikiran yang terhegemoni oleh empirisme barat, tetapi sebagai paradigma berpikir yang saling bersisian. Dapat dikatakan telah terjadi emansipasi kebudayaan masyarakat Toraja yang cenderung dianggap primitif (dengan sendirinya sebagai budaya yang inferior) dalam paradigma logis pada narasi cerpen ini.

Posisi bersisian yang dimaksud di atas tidak dapat secara serampangan disimpulkan bahwa narasi cerpen ini sepenuhnya menggunakan paradigma berpikir orang Toraja dalam bentuk yang paling murni. Di Amerika Latin, realisme magis hadir dengan kesadaran bahwa tidak ada budaya yang dapat ditelusuri hingga ke bentuknya yang paling murni. Oleh karena itu, realisme magis sangat berfokus pada silang budaya daripada ragam budaya. Realisme magis menggabungkan banyak hal dalam dunia rekaannya, seperti penggabungan primitif dan modern. Namun, sesungguhnya secara ontologis, realisme magis menggugat batasan realisme dengan menggabungkan yang realis dan yang magis. Dalam cerpen ini, hal itu dapat ditemukan pada banyak unsur riil yang memiliki ciri utama paradigma berpikir logis, yaitu keterukuran, bahwa penanda waktu menjadi yang paling menonjol dalam narasi Di Tubuh Tarra dalam Rahim Pohon.

Penanda waktu pertama adalah bertahun-tahun. Bertahun-tahun berarti berlangsung terus-menerus. Mayat-mayat bayi dalam pohon tersebut bertahun-tahun digambarkan menyusu getah dari pohon tarra, hingga tubuh mereka menyatu dengan batang pohon, dan batang pohon tersebut kembali utuh hingga mayat bayi baru dapat dikubur lagi di dalamnya. Penanda waktu kedua adalah beberapa hari lalu. Beberapa hari lalu menjadi penanda waktu riil kematian Runduma. Penanda waktu ketiga adalah malam. Malam menggambarkan peristiwa saat ambe dan indo Runduma diharuskan menikah karena melanggar hukum adat. Di sinilah bermula penderitaan dalam keluarga Runduma, hingga Runduma harus meregang nyawa. Penanda waktu keempat adalah Agustus. Agustus menggambarkan bulan saat menjelang musim hujan. Bulan ini menjadi indikasi bahwa daun-daun Indo yang dikonotasikan sebagai rambut berguguran dan juga menandakan bahwa Runduma telah tinggal berbulan-bulan di pohon tarra tersebut. Penanda kelima adalah pagi. Pagi menjadi penanda pergantian hari dalam dunia riil dan dalam dunia Runduma dan Lola Toding yang telah berada di dunia lain.

Namun, pada sisi lain konvensi tentang waktu yang jamak ditemukan dalam masyarakat modern tersebut dibatalkan pula dengan berbagai kejadian yang menyalahi logika waktu linear. Kekacauan waktu hadir saat Runduma meninggal dalam dunia riil, lalu Lola Toding yang berada di dunia magis melihat kejadian tersebut. Hadirnya hal magis, yakni Lola Toding saat kematian Runduma, menjadi gangguan atas waktu modern.

"Beberapa hari yang lalu, kau meninggal_entah sebab apa. Kulihat kerabatmu menegakkan eran di tubuh Indo untuk mereka panjati (Faisal Oddang, 2016)". 
Meskipun penanda waktu didominasi oleh logika keterukuran barat, dalam cerita terdapat fakta-fakta yang mengakibatkan terjadinya perusakan konvensi alur waktu (disruption of time). Kedewasaan psikologi yang ditunjukkan oleh mayat-mayat bayi tersebut dan Runduma dan Lola yang terkesan sebaya meskipun terpisah jauh jarak kematiannya menyalahi logika linier alur waktu modern. Terdapat keraguan yang sulit dipertemukan dalam memahami waktu di cerpen ini (unsettling doubt) akibat tabrakan dua paradigma berpikir dari dua masyarakat yang berbeda, sementara kemampuan Runduma dan Lola Toding melihat dunia riil menyebabkan ruang riil rusak karena dirembesi hal-hal magis. Meskipun Runduma telah meninggal berhari-hari, bahkan berbulan-bulan, dan Lola hanya tinggal tulang-belulang, mereka dapat memasuki ruang-ruang riil dan melihat peristiwa masa kini. Konsep mengenai ruang digugat dari sebatas pada objekobjek terindera menjadi lebih luas yang mencakupi semua ruang lain seperti passiliran (ruang antara) dan surga yang tidak terinderai.

Dalam cerpen ini unsur-unsur realis dan unsur-unsur magis dihadirkan sebagai unsur yang bersebati dalam objek maupun tokoh-tokohnya. Kehadiran kedua unsur tersebut yang kemudian melahirkan keraguan antara magis dan riil bagi pembaca. Keraguan ini akan sangat dipengaruhi oleh konteks budayanya. Jika akrab dengan budaya logis empiris, ia terasing dengan logis magis, demikian sebaliknya. Kehadiran magis yang dalam fiksi tidak akan terasa janggal jika logika magis dan mistis hadir dalam kesehariannya. Hal inilah yang dihadirkan dalam realisme magis yang dipicu oleh sistem kepercayaan berbeda.

\section{Relasi Antarelemen dan Kadar Realisme Magis dalam Cerpen Di Tubuh Tarra dalam Rahim Pohon}

Relasi antarelemen dari kelima elemen-elemen realisme magis akan menunjukkan hubungan dunia magis dan dunia riil. Relasi ini menggambarkan posisi magis dan posisi riil dalam cerita. Pada unsur elemen magis yang tak tereduksi, tidak ada unsur yang dapat direduksi kemagisannya karena tidak adanya komentar, perdebatan, atau kooptasi yang menegasi kehadirannya, sehingga elemen-elemen tersebut tetap menjadi elemen magis yang tak tereduksi.

Dunia yang fenomenal yang digambarkan dalam cerpen ini seakurat dunia riil. Benda-benda dan tokoh-tokoh yang dihadirkan membuat pembaca fiksi realis bereaksi familiar dengan narasi tersebut dan menganggap representasi tersebut seakurat dunia riil. Elemen realisme magis yang ketiga adalah keraguraguan antara magis dan riil. Keraguan tersebut karena penulis menghadirkannya dalam dunia riil dan magis seperti tanpa sekat. Keduanya seperti hadir bersamaan pada dunia riil dan magis dengan fungsi yang tak berubah. Demikian halnya dengan penggabungan dunia-dunia, tokoh dan tempat yang riil serta magis seperti melebur. Tokoh dan tempat berada di tengah dan menggabungkan atau meleburkan magis dan riil. Kekacauan waktu dan ruang juga terjadi saat pertemuan magis dan riil.

Narasi magis dan riil dalam cerpen Di Tubuh Tarra dalam Rahim Pohon digambarkan seperti dua dunia yang berjalan bersisian. Keberadaannya diakui dalam narasi dan tidak ada pemisahan. Keduanya seperti kehidupan yang samasama berjalan dalam ruang dan waktunya masing-masing. Adapun kadar realisme magis dalam cerpen ini dapat diukur dengan melihat kecenderungan tokohtokoh, benda-benda, dan peristiwaperistiwa. Gradasi posisi magis dan riil akan menjadi penentu apakah cerpen ini realis atau magis ataukah realisme magis. Untuk itu, kesatuan cerita perlu diteliti.

$$
\text { Cerpen diawali dengan }
$$
mengisahkan dunia magis dalam pohon tarra yang menjadi kuburan bagi anakanak bayi. Lola Toding sebagai narator 
dalam cerpen ini adalah seorang mayat bayi yang telah menghuni pohon tersebut bertahun-tahun. Wujudnya bahkan telah berupa tulang-belulang. Kehadiran Runduma sebagai mayat baru penghuni tersebut menghadirkan wacana betapa konstruksi tradisi yang kapitalis telah menjadi penyebab kematian salah seorang bayi, yakni Runduma. Mereka mempertentangkan tradisi yang membelenggu masyarakat pendukungnya dan kehidupan modernitas. Hukum adat telah menjadi penyebab ambe dan indo Runduma bertengkar hebat dan menyebabkan Runduma meninggal karena mereka terlilit utang yang membuat frustrasi. Padahal, apa salahnya hanya melaksanakan syarat nikah tanpa harus dilabeli dengan dua belas kerbau dewasa karena yang akan menikah tidak sanggup membeli kerbau-kerbau tersebut. Tidak hanya itu, budaya yang telah menghegemoni masyarakat juga menjadi penyebab ambe Runduma mencuri tulangbelulang karena harganya hingga ratusan juta rupiah. Runduma dan Lola Toding terjerat tradisi, tetapi mereka tidak dapat bernegosiasi. Pengetahuan-pengetahuan lokal lebih mendominasi.

\section{PENUTUP}

\section{Simpulan}

Hasil analisis terhadap cerpen $D i$

Tubuh Tarra dalam Rahim Pohon karya Faisal Oddang menggunakan lima elemen realisme magis oleh Wendy B. Faris menunjukkan 1) adanya elemen-elemen tak tereduksi, dunia yang fenomenal, keragu-raguan antara magis dan riil, penggabungan dunia-dunia, dan kekacauan waktu, ruang dan identitas berupa objek, karakter, dan peristiwa serta 2) relasi antarelemen menunjukkan bahwa objek, karakter, dan peristiwa antara yang banyak mendominasi karya ini sehingga dapat disimpulkan bahwa kadar realisme magis cerpen ini cukup kuat untuk dikategorikan sebagai karya realisme magis.

Tulisan ini masih perlu referensi yang lebih banyak agar kajian mengenai kadar realisme magis tidak hanya bergantung pada data primer, yakni cerpen, tetapi referensi lain mengenai tradisi Toraja juga diperlukan agar benar-benar memahami apakah yang terjadi adalah realitas, atau magis, ataukah gabungan keduanya.

\section{DAFTAR PUSTAKA}

Albert Sheqi. 2013. "Magic Realism in Toni Morrison's 'Song of Solomon'." Lingua Mobilis, 1(40). Retrieved from http://booksc.org/book/50348924/433 Oae.

Faisal Oddang, dkk. 2016. Cerpen Pilihan Kompas 2014: Di Tubuh Tarra dalam Rahim Pohon. Jakarta: Kompas.

Faruk. 2012. Metode Penelitian Sastra: Sebuah Penjelajahan Awal. Yogyakarta: Pustaka Pelajar.

Gabriel Garcia Marquez. 2014. Obituari. PT Sagang Intermedia Press, 63.

Maggie Ann Browers. 2005. Magic(al) Realism. New York: Taylor \& Francis e-Library.

Marisa Bortolussi. 2011. "Introduction: Why We Need Another Study of Magic Realism". Canadian Review of Comparative Literature, 30(2), 279293. Retrieved from https://journals.library.ualberta.ca/crcl /index.php/crcl/article/download/1067 $0 / 8227$

Muchtar Lubis. 2017. Manusia Indonesia (Sebuah Pertanggungjawaban): Ceramah pada Tanggal 6 April 1977 di Taman Ismail Marzuki-Jakarta. Jakarta: Yayasan Pustaka Obor.

Warnes, C. 2009. Magical Realism and the Postcolonial Novel: Between Faith and Irreverence. US: Palgrave Macmillan.

Wendy B. Faris. 2004. Ordinary Enchantments: Magical Realism and the Remystification of Narrative. USA: Vanderbilt University Press 
Telaga Bahasa Vol. 7, No. 2, Desember 2019: 151--162 